\title{
International Primary Care Respiratory Group (IPCRG) Guidelines: Management of Asthma
}

\author{
Thys van der Molen ${ }^{a, b, *}$, Anders Østrem ${ }^{b}$, Bjorn Stallberg $^{c}$, \\ Marianne Stubbe Østergaard ${ }^{d}$, Raj B. Singh ${ }^{\mathrm{e}}$
}

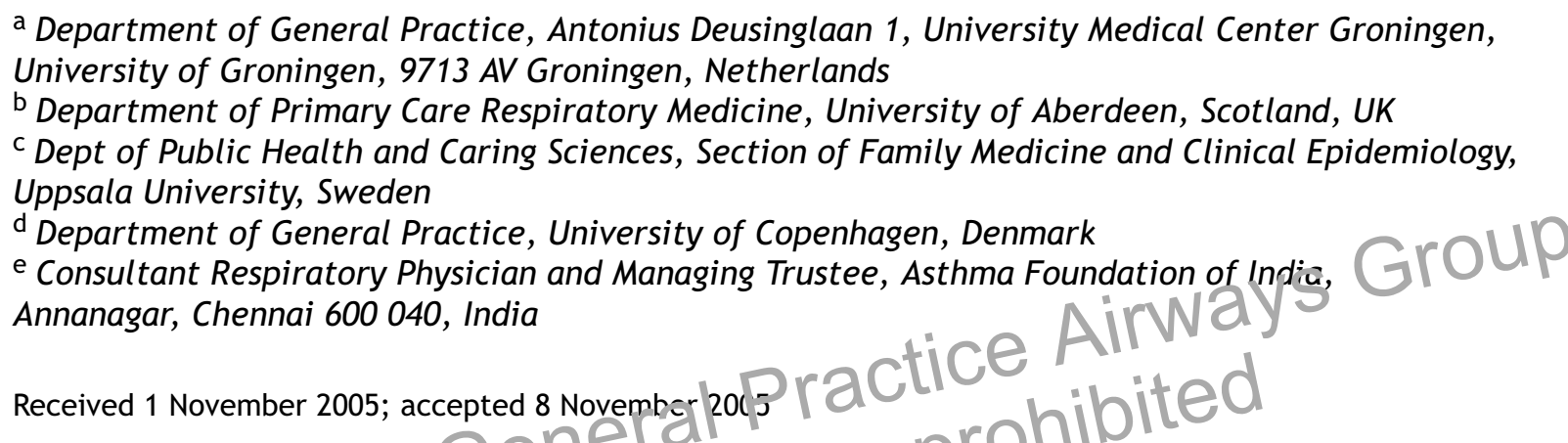

a Department of General Practice, Antonius Deusinglaan 1, University Medical Center Groningen, University of Groningen, 9713 AV Groningen, Netherlands

b Department of Primary Care Respiratory Medicine, University of Aberdeen, Scotland, UK

c Dept of Public Health and Caring Sciences, Section of Family Medicine and Clinical Epidemiology,

Uppsala University, Sweden

d Department of General Practice, University of Copenhagen, Denmark

e Consultant Respiratory Physician and Managing Trustee, Asthma Foundation of India,

Annanagar, Chennai 600 040, India

Received 1 November 2005; accepted 8 Novembor 201

KEVyoRDS
Gu deline;
Primary care;
General practice;
Asthma;
Classification;
Management;
Treatment;
Adults;
Children

Summary Nolldvide, most patients with asthma are treated in primary are. Optimal primary care management of asthma is therefore of considerable importance. This IPCRG Guideline paper on the management of asthma in primary care is fully consistent with GINA guidelines. It is split into two sections, the first on the management of adults and schoolchildren, and the second on the management of pre-school children. It highlights the treatment goals for asthma and gives an overview of optimal management including the topics which should be covered by the primary care health professional when educating a patient about asthma. It covers the classification of the disease, the stepwise approach to pharmacologic therapy, disease monitoring, the management of exacerbations, and the identification of patients at risk of asthma death.

(c) 2005 General Practice Airways Group. Published by Elsevier Ltd. All rights reserved.

\section{Background}

Primary care physicians treat the majority of patients with respiratory diseases. However, in

\footnotetext{
* Corresponding author. Tel.: +31503637478; fax: +31503632964.

E-mail address: T.van.der.Molen@med.umcg.nl (T. van der Molen).
}

most countries, specific primary care guidelines are not available. Since clinical management which follows evidence-based guidelines yields better results for patients, it is important to have access to primary care guidelines which are specifically relevant to, and provided by, primary care. The International Primary Care Respiratory Group (IPCRG) asked primary care experts from several countries to develop primary care guidelines for 
the diagnosis and treatment of asthma, chronic obstructive pulmonary disease (COPD), and rhinitis. A brief summary of the expert report (which took three years to complete) was published as a handbook [1] in 2005.

This paper is devoted to primary care asthma management and it has been specifically written for primary care health professionals. It is consistent with the GINA guidelines [2], which we recommend should be consulted if a more detailed perspective is required. In addition to this section on asthma, the IPCRG guidelines consist of papers on the diagnosis of respiratory diseases in primary care [3], and the management of COPD, [4], and rhinitis [5]. For the specific purpose of ranking the evidence in each of these publications, we have used the so-called Three Star System of the Royal College of General Practitioners [6] in order to score the evidence of the statements made (see box).

Three Star System of the Royal College of General Practitioners:

\begin{tabular}{|c|c|}
\hline $\begin{array}{l}\text { Evidence } \\
\text { Base }\end{array}$ & $\begin{array}{l}\text { Royal College of General Practitioners. } \\
\text { The development and implementation } \\
\text { of clinical guidelines. Report of the } \\
\text { clinical guidelines working group. } \\
\text { London, 1995, RCGP [6]. }\end{array}$ \\
\hline $\begin{array}{l}\text { *** Strong } \\
\text { evidence }\end{array}$ & $\begin{array}{l}\text { Provided by generally consistalt } \\
\text { findings in multip!e }\end{array}$ \\
\hline & 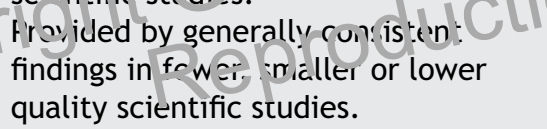 \\
\hline $\begin{array}{l}\text { * Limited } \\
\text { evidence }\end{array}$ & $\begin{array}{l}\text { Provided by one scientific study or } \\
\text { inconsistent findings in multiple } \\
\text { scientific studies. }\end{array}$ \\
\hline $\begin{array}{l}\text { - No } \\
\text { scientific } \\
\text { evidence }\end{array}$ & $\begin{array}{l}\text { Based on clinical studies, theoretical } \\
\text { considerations and/or clinical } \\
\text { consensus. }\end{array}$ \\
\hline
\end{tabular}

\section{Management of Adults and Children}

\section{Introduction}

Asthma can have a significant impact on individuals and their families. Although there is no cure for most people with asthma, the exception being those with occupational asthma, appropriate management will result in control of symptoms and the underlying airway inflammation in the majority of patients [2] $]^{* * *}$. Worldwide, most patients with asthma are treated in primary care. Optimal management of patients in this setting is therefore of considerable importance in reducing the burden posed by asthma both to individuals and to society $[7,8]$.

Once asthma has been diagnosed [3], it should be classified as being 'intermittent', 'mild persistent', 'moderate persistent', or 'severe persistent', based on an assessment of symptoms, available lung function measurement, and, when treated, the response to treatment [2]. Severity of asthma will determine the type of treatment required.

\section{Treatment goals}

The goals of successful management of asthma are to:

- Relieve symptoms

- Prevent and treat exacerbations

- Allow normal activity levels

- Prevent mortality

- Avoid adverse effects from medications

- Prevent disease progression.

\section{Overview of Management}

Asthma management has a number of interrolated components:

- Education andadice

- Hicnioring control through assessment of symptoms and $r \in$ dicalion use

- Fostricti: hing individual disease management plans

- Establishing individual plans for managing exacerbations

- Facilitating smoking cessation.

\section{Education and advice}

Ongoing patient education is the key to creating a partnership between patient and healthcare professional which can then contribute to successful asthma care. The management of patients with asthma can be delegated partly to trained practice nurses [9]. In addition, since the general practitioner (GP) provides long-term continuity of primary care relating to all aspects of patients' health, in many countries the GP is particularly well placed to provide effective asthma education. When educating a patient about asthma, the following topics should be covered:

General information about asthma. In general, asthma can be treated easily. Patients need to be aware that symptoms can be triggered by allergens and non-specific triggers such as smoke, dust and exercise. However, taking part in sport should still be possible for the majority of asthma patients and is recommended. How patients perceive and manage their disease should be discussed - for 
example, issues such as functional impairment because of the fear of breathlessness or cough, and being ashamed to use medication in the company of other people.

Purpose of medication. For intermittent symptoms, rapid-acting beta- 2 agonists can be used. These drugs are very effective for immediate relief, but do not treat the underlying inflammation which is the fundamental pathology of the disease. Inhaled corticosteroids are very effective in treating inflammation and should be used when the patient has symptoms on a regular basis $[10]^{* * *}$. It is essential that an individually-assessed minimal dosage of inhaled corticosteroids is used on a daily basis $[11]^{* * *}$. Daily compliance with prescribed treatments, and having an optimal inhalation technique, are the keys to effective treatment $[12]^{* * *}$.

Inhalation technique. Ask patients to bring their medication to every asthma review, for assessment, and if necessary, correction, of inhalation technique. Failure to achieve treatment goals is often due to incorrect inhalation technique [13]".

Self-management plans. Self-management plans for those with moderate to severe asthma have a positive impact on asthma-specific quality of life, reducing the number of exacerbation: a a hospitalisations [14] ${ }^{* * *}$.

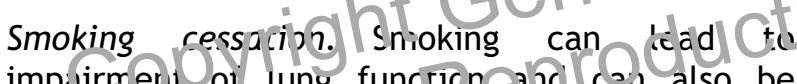
impairment of lung function a ic l can also be a non-specific trigger causıng exacerbation of symptoms $[15]^{* *}$. Facilitating smoking cessation is therefore important. Advice should be given on effective ways to stop smoking and how to avoid smoke-polluted environments [16] ${ }^{* * *}$.

Allergens. Advice should be given on avoiding exposure to specific allergens and triggers [17]". When a patient has a proven allergy to a specific allergen, avoidance of this allergen should be recommended. Special attention should be paid to the sleeping area, especially the mattress and bedding, as well as dampness and cleanliness in the house.

Therapy. Inhalation devices are important for treating asthma. There are three main options:

i. Dry Powder Inhalers (DPI);

ii. Metered Dose Inhalers (MDI), some of which are breath-activated, and

iii. MDI with a spacer.

With a DPI, the dose and mean particle diameter depends on respiratory airflow. With a simple MDI, the dose and mean diameter are not dependent on patients' ability to inhale; lung deposition depends in the main on hand/breath co-ordination. An $M D I$ with an appropriate spacer can alleviate the problems of poor hand/breath co-ordination. There are no substantial differences in the effectiveness and side effects of treatments delivered through these different devices [13].

Inhalation instructions. Patients should be given the following advice when being issued with inhalation devices:

- DPI and breath-activated MDI: take a deep and forced inhalation.

- Simple MDI: shake before use, place mouthpiece in mouth, inhale slowly when you press on the dose inhaler, and keep your breath for at least five seconds after inhalation.

- MDI with spacer: shake the MDI, spray 1 puff in the spacer and inhale directly afterwards in order to avoid deposition of the drug on the walls of the spacer.

Symptomatic treatment. There are three groups of bronchodilators: beta-2 agonists, anticholinergics, and theophyllines The e drugs decrease broncho-constriction, but $\mathrm{T}$ dve enther no or very limited an ti-inflam matory activity.

Mairte cence treatment: with beta-2 agonists C. Whe may lead to ta $\mathrm{d}=$ cline of lung function in patients vith muderate and severe asthma. High (loses of beta-2 agonists can lead to side effects such as headache, tremor and increased heart rate.

There are two anticholinergics availableipratropium bromide and tiotropium bromide-of which tiotropium bromide is the longer acting; neither drug is fast acting. These drugs have very few side effects, but they are not recommended as first-line treatment in asthma (see GINA guidelines online: http://www.ginasthma.org) [2]. Theophyllines are not recommended as first-line treatment because of the small therapeutic range and the associated side effects. However, in some countries, availability and price considerations might favour use of theophyllines as a first-line symptomatic treatment.

For maintenance treatment of asthma, oral (tablet and syrup) bronchodilators should if possible be replaced by inhaled bronchodilator formulations.

Preventive therapy. The most effective preventative therapy is inhaled corticosteroids $[10,18]$. Side effects associated with inhaled corticosteroids are seldom seen in dosages up to $400 \mathrm{mcg}$ beclomethasone (or equivalent) daily [19]. Higher dosages can result in a range of side effects including oral candidiasis and skin thinning 
or bruising. Side effects and the fear of side effects may be important factors in the acceptance of, and compliance with, inhaled corticosteroids. An alternative for inhaled corticosteroids is to use leukotriene receptor antagonists [20].

Maintenance treatment with oral corticosteroids has many side effects and is not recommended.

Asthma and pregnancy. Little is known about the risks of asthma medications on the foetus. Beclomethasone, budesonide [21] and short-acting beta-2 agonists can be prescribed during pregnancy [22]. With acute and serious asthma, the avoidance of hypoxia is relatively more important than the avoidance of steroids.

\section{Pharmacological Therapy: Stepwise Approach}

Some patients present with intermittent symptoms only. This is different from persistent asthma when patients present with symptoms that occur more than once a week.

Step 1: Intermittent asthma; symptoms $\leq$ once per week

When patients present with infrequent symptoms, prescribe rapid-acting beta- 2 agonists. In patients over 60 years of age, anticholinersics can be considered as an alternative. Prescribe a rapid-acting beta-2 $a € \Leftrightarrow)$ ist for patients with exercise-nd $\mu_{e d}$ asthma. Oshas ina!ll,

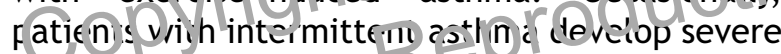
exacerbations; these pitierics should be treated as if they had persistent asthma.

\section{Step 2: Mild persistent asthma;} symptoms > once per week

When patients present with more frequent symptoms, start with inhaled corticosteroids in a low dose: $200-400 \mathrm{mcg}$ of beclomethasone or equivalent $[23]^{* * *}$. If inhaled corticosteroids fail to improve asthma after a period of three months, ascertain the reason why. In patients believed to have good compliance, a satisfactory inhalation technique, and no identified trigger factors for their asthma, treatment should be extended to Step 3.

\section{Step 3: Moderate persistent asthma}

The Step 2 treatment goal has not been reached despite low dose of inhaled corticosteroids and appropriate compliance. The preferred treatment is regular treatment with a combination of inhaled glucocorticsteroid and a long-acting beta-2 agonist $[24,25]^{* * *}$. Alternatives are combinations of inhaled corticosteroids with sustained release theopyllines or with leukotriene receptor antagonists [20 $]^{* *}$.

\section{Step 4: Severe persistent asthma}

When Step 3 treatment goals have not been reached despite combination therapy with inhaled corticosteroids in a low or medium dose and a long-acting beta-2 agonist, patients need special attention. Ensure that every effort has been made to facilitate avoidance of triggers and to promote adherence with treatment. Ensure also that patients have a personalised asthma treatment plan. If patients still suffer from frequent symptoms and/or exacerbations, the preferred treatment is a combination of high dose inhaled corticosteroids plus a longacting inhaled beta-2 agonist twice daily [26]". Other possible add-on treatments are sustained release theophyllines and leukotriene receptor antagonists." For shorter periods of time, oral corticosteroids (prednisolone $30 \mathrm{mg}$ daily for 7-14 days) can be used to assess the scope for symptom control. ${ }^{* *}$ This is a cheap and very effective way to assess the possibility of improving the underlying asthmatic inflammation of the bronchial tree.

\section{Monitoring}

- Patients with indermittent asthma who are in head of frequent use of bronchodilators should be invitlod for an cistma review.

rat ents with persistent asthma need to be monitored every three months until treatment goals have been achieved. After this the patient should be monitored annually [27]*.

- Monitoring consists of:

- Evaluation of symptoms (by day and by night)

- Functional status and any limitations

- Frequency of need to take reliever medication

- Discussion of any relevant self-medication taken and complementary care being sought

- Avoidance of triggers - allergen and nonallergen

- Evaluation of side effects of prescribed medication

- Titration of dosage of inhaled corticosteroid

- When the patient suffers from local, or even systemic, side effects of inhaled corticosteroids, decreasing the dose of inhaled corticosteroids is recommended, or a switch to another brand or inhalation device

- Assessment of inhalation technique

- Peak expiratory flow (PEF) measurement or spirometry

- For patients in whom treatment goals cannot be achieved, it is important to investigate why this is so. If needed, the dosage of inhaled corticosteroids can be changed. 
- When treatment goals have been achieved, the dosage of inhaled corticosteroids can be halved.

- Self-management plans should be evaluated at each visit and patients should be instructed that when they are not successful in managing an asthma exacerbation effectively, medical advice should be sought.

\section{Referral}

- Reconsider the diagnosis and treatment when treatment goals have not been achieved after three months of optimal treatment. Consider the need for a specialist assessment.

\section{Management of Exacerbations}

\section{Key features of exacerbations}

Exacerbations of asthma are episodes of increased symptoms characterised by shortness of breath, wheezing, cough or chest tightness. In some patients, an exacerbation can produce only some of these symptoms. Airflow limitation can be measured objectively by a decrease in PEF or forced expiratory volume in one second (FEV1) $[28,29]$. Measurements of lung function are more reliable indicators of severity than the degree of symptoms. The onset of symptoms may, hov'ever, be a more sensitive marker of the et are of an exacerbation since $\mathrm{D}$ resience 7 , symptoms ofte? precedes a deftele, $n$ lung function [30]

The cevericy of exa-cran may range from mild to life-threatening. Deterioration usually progresses over hours or days, but may occasionally occur precipitously over minutes. Acute exacerbations usually reflect exposure to a trigger-most often a viral infection or an allergen-but an exacerbation with a more gradual pattern of deterioration may reflect failure of longterm management. Morbidity and mortality are most often associated with failure to recognise the severity of the exacerbation, inadequate attention paid to seeking appropriate help urgently, and under-treatment $[31-33,88]$.

\section{Patients at high risk for asthma-related death}

Some patients have increased risk of asthma-related death, and particular care should be taken to ensure that they are treated optimally, monitored closely and given education on the routine and emergency management of exacerbations. ${ }^{* * *}$ These include those patients:

- With a past history of near-fatal asthma requiring intubation and/or mechanical ventilation. This puts patients at a clear increased risk of needing intubation during subsequent exacerbations [31]

- Who have had a hospitalisation or emergency care visit for asthma in the past year

- Who are currently using or have recently stopped using oral corticosteroids

- Who are not currently using inhaled corticosteroids, which appear to offer a protective effect against death or near-fatal asthma [32]

- Who are over-dependent on rapid-acting inhaled beta- 2 agonists, especially those who use more than one canister of salbutamol (or equivalent) monthly [33]

- With a history of psychiatric disease or psychosocial problems, including the use of sedatives $[34,88]$

- With a history of poor compliance with issued asthma medication plans.

Assessment of severity of the exacerbation Indices of severity - particularly PEF, respiratory rate, and pulse oximetry [35] - should be monitored during treatment. Any deterioratipminay require prompt intervention,

The followirg indicale $h$. $i t$ the attack is severe: Brea-blessness at rest or a respiratory rate greater than $3 \sigma$, in inte

Huncled forward, talking in words rather than sentences

- Wheeze is loud or absent

- Pulse is slow (define) or greater than $120 / \mathrm{min}$.

- PEF is less than $60 \%$ of predicted or personal best

- Exhaustion, agitation, drowsiness or confusion.

Management of exacerbations at home

Initiation of appropriate therapy at the earliest possible signs of deteriorating asthma control is important for the successful management of asthma exacerbations. When patients are able to begin treatment at home, this not only avoids delaying treatment, but also aids the sense of control they have over their asthma. The degree of care provided in the home will depend on the health care professional's and patient's (or parents') experience, and the availability of medications and emergency care.

Home PEF measurements should be an integral part of home management strategies, although the degree of symptoms is a more sensitive detector of the early stages of an asthma attack than is change in PEF [36]. Ideally, all patients should have a written action plan with both a symptom and a peak flow component [36] that outlines how and when to: 
- Recognise signs of deterioration

- Modify or augment treatment

- Assess the severity of the attack

- Obtain more specialised care if appropriate.

\section{Treatment}

Bronchodilators. For moderate exacerbations, repeated administration of rapid-acting inhaled beta- 2 agonists (two to four puffs every 20 minutes for the first hour) is usually the best and most cost-effective method to achieve rapid reversal of airflow limitation. After the first hour, the dose of beta- 2 agonist required will depend on the severity of the exacerbation. Mild exacerbations will respond to two to four puffs every 3 to 4 hours; moderate exacerbations will require six to 10 puffs every 1 or 2 hours; for more severe exacerbations, up to 10 puffs (preferably given through a spacer), or full doses given via nebuliser, may be required at less than hourly intervals. Bronchodilator therapy delivered via an MDI, ideally with a spacer, produces at least an equivalent improvement in lung function as the same dose delivered via nebuliser $[37,38]$. Depending upon the proportion of patients able to use an MDI, this route of delivery is also likely to be more cost-effective than via nebulizer [39]. No additional medication is necessary if the rapidacting inhaled beta- 2 agonist produces a compitets or near-complete response (PEF retırns \& greater than $80 \%$ of predicted or Fo(sonal Lest) and the resnonse lasts al least 3 to 4 hours.

corticusteroids. A nun Dereostudies indicate benefit from action plans that integrate an increase in inhaled corticosteroids early in an asthma exacerbation [36]". The data to support the effectiveness of this strategy are, however, limited [40]. Oral corticosteroids $(0.5$ to $1 \mathrm{mg} / \mathrm{kg}$ prednisolone or equivalent during a 24-hour period) should be used to speed resolution of all but the mildest exacerbations [2] $]^{* * *}$. A useful rough guide is to use oral corticosteroids if the response to the rapid-acting inhaled beta- 2 agonist alone is either not prompt or not sustained (e.g. PEF less than $80 \%$ of predicted or personal best after 1 hour).

\section{Additional care}

If there is sustained improvement in symptoms and PEF, care may be continued at home. Full recovery from the exacerbation is often gradual, and medications for the exacerbation may need to be continued for several days to sustain relief of symptoms and improvement in PEF. There should be no delay in seeking medical help if the:

- Patient is at high risk for asthma-related death
- Exacerbation is severe (e.g. PEF remains less than $60 \%$ of predicted or personal best after beta- 2 agonist therapy)

- Response to the bronchodilator is not prompt and/or is not sustained for at least 3 hours

- There is no improvement within 2 to 6 hours after corticosteroid treatment is started

- There is further deterioration.

\section{Management of Pre-school Children}

\section{Introduction}

Whilst the underlying pathophysiology of asthma is the same for adults and children, the rapid growth and development occurring in infants and pre-school children requires specific consideration. Furthermore, the diagnosis of asthma in children aged under 6 years is difficult and may not be definitive, and requires the primary care physician to be vigilant regarding the possibility of alternative diagnoses. In particular, the difference between transient wheeze and true asthma is difficult to make in this age group. Likewis, the manayement of asthma at these arly ages is challenging. Treatment ficus must be individualised, taking into account disetsesererity, the benefits, risks, and ayalainit ty oi each treatment, cultural preferences, and the characteristics of the health care system.

\section{Treatment goals}

The goals for successful management of pre-school asthma are:

- Minimal or no symptoms, including night-time symptoms

- No emergency visits to physicians or hospitals

- Minimal need for reliever medications

- No limitations on physical activities and exercise

- Minimal or no medication side effects.

\section{Education and advice}

Optimal asthma management requires a partnership between the child's parents and primary healthcare professionals. The aim is for parents to have the knowledge and ability to control the child's asthma, under the guidance of the healthcare professional.

Simple educational interventions designed to teach self-management skills have been shown to reduce significantly hospital morbidity and readmission [41]. Educational methods must be 
age-appropriate, and for young children with asthma this will likely mean focusing educational efforts on the child's parents. On-going education, offered at every visit, is the key to successful asthma management. Individualised asthma plans should be based on symptoms. Primary care physicians can play a key role in educating children and their parents regarding the following:

- Proper use of inhalers and spacers. This includes demonstrating proper use, providing illustrated instructions, and asking patients to demonstrate their technique at each visit

- Self-management to prevent attacks. This includes how to avoid asthma risk factors and triggers, and regular use of daily medications (if any)

- Action steps to stop attacks. This includes how to recognise and treat worsening asthma, and how and when to seek medical attention.

Additionally, parental education can be reinforced with a variety of methods such as discussions with other healthcare workers, practical demonstrations, written materials, classes, video or audio tapes, and patient support groups.

\section{Non-pharmacological treatment}

While pharmacologic treatmere is eifective in treating asthma, r in pharmacologic measille: cail also imfors symptom cortro' ald quaciuy of life for asthmatic patients. In particular, preventing exposure to asthma triggers (e.g., risk factors such as allergens and irritants that make asthma worse) can improve asthma control and reduce medication needs.

Reducing exposure to environmental tobacco smoke (i.e. passive smoke) is the most important measure that can be taken to reduce exposure to asthma risk factors. Passive smoking increases the risk of allergic sensitisation in children $[42,43]$. Avoidance of indoor allergens (e.g. dust mites, animal allergens) may also reduce asthma symptoms, although there is conflicting evidence regarding the effectiveness of measures to control exposure to indoor environmental allergens $[44,45]$.

\section{Pharmacological treatments}

In comparison with the extensive research literature on the treatment of asthma in adults and older children, asthma treatment in infants and pre-school children has been inadequately studied. Given the physical and cognitive growth and development of the young child in the pre-school years, use of all pharmacological treatments must be especially considered in terms of their beneficial and potential adverse effects, both short-term and long-term.

Stepwise treatment is recommended in order to gain and maintain symptom control. The choice of medication should take into consideration current treatment, pharmacologic properties, availability of anti-asthma treatments, and economic considerations. Severity of symptoms determines the type of treatment required, since lung function cannot reliably be measured in pre-school children.

As in adults, asthma in this age group should be classified as: intermittent; mild persistent; moderate persistent; and severe persistent [2]. For children who are already receiving treatment, severity classification should be based both on clinical features as well as the "step" of the daily medication regimen on which the child is currently maintained. Prior to "stepping up" with the addition of other medications, healthcare professionals should check compliance with current medications, proper inhaler tech licue cilc nake appropriate attemnts to minise the impact of known trigser fuctors.

The préerred device our administering inhaled asthma medication for iniants and young children is a rressurised MDI with a spacer and face mask. As the child's ability to co-operate improves (often around the age of 4-6 years), a spacer with a mouthpiece can be used rather than a face mask [2]. Nebulisers are not preferred for maintenance treatment. However, for infants and young children where even passive co-operation cannot be achieved, the loose face mask of a jet nebuliser can provide an alternative that is more acceptable to the child than the close-fitting face mask of a spacer. Additionally, nebuliser treatment is preferred for all infants and most children during severe acute asthma.

\section{Controller medications}

Inhaled corticosteroids. There is ample evidence from randomised controlled trials which documents clinically significant improvements in health outcomes from the use of inhaled corticosteroids in pre-school children with asthma [46-52]. There are few data available regarding the side effects of inhaled corticosteroids on growth in infants and young children. While extensive study of the growth effects of inhaled corticosteroids in school children suggests no statistically or clinically significant adverse effect at low doses (i.e.100 to $200 \mathrm{mcg} /$ day [53-60]) these findings cannot be 
extrapolated directly to infants and pre-school children owing to the more rapid growth rate and differences in metabolism in the younger age group. Therefore, when inhaled corticosteroids are used to treat young children, the smallest effective dose of inhaled corticosteroids should be used, and the child's growth and height should be monitored regularly. In addition, if adequate control is not achieved at a dose of $400 \mathrm{mcg} /$ day, consideration should be given to the addition of other controller agents to the inhaled corticosteroid regimen. These agents (described below) can be used as an adjunct prior to increasing the inhaled corticosteroid dosage further.

Systemic corticosteroids. Use of systemic (oral) corticosteroids in treating children of any age is limited to acute exacerbations, whether viralinduced $[61,62]$ or otherwise $[63,64]^{* * *}$.

Leukotriene modifiers. In children aged 2 and older with moderate or severe disease in whom asthma is insufficiently controlled by a low dose of inhaled corticosteroids, leukotriene receptor antagonist therapy can lead to moderate improvements in lung function $[62,65-67]^{* *}$. These agents have not been studied as monotherapy in children of any age with mild persistent asthma so there is no evidence to support their usc as monotherapy. One study on the use of mon telukast in children aged 3 to $D \in$ a:s sowed that it provides clinically isinificant broncho-brotecticr. in thi:asegijoup [\$8]".

cromones. Sodium cromoglycate and nedocromil sodium have limited roles in long-term treatment of childhood asthma. There are few studies that have been performed with these agents in preschool children, and the results have been conflicting.

Methylxanthines. Theophylline has a limited role in long-term treatment of children with asthma, but its low cost may justify more frequent use in some countries. In pre-school children, there is some evidence of clinical benefit (i.e. bronchodilation) from theophylline, but further randomised controlled trials are required to determine optimal dosing and benefits relative to other treatments. Use of these agents in young children requires careful individualised attention to the doses required to achieve therapeutic levels whilst avoiding side effects.

Long-acting inhaled beta-2 agonists. These agents may be useful in some children with asthma, and are primarily used as add-on therapy in combination with inhaled corticosteroids, either as maintenance treatment or as single-dose therapy before vigorous exercise." However, the
GINA guideline concludes that there is insufficient evidence for the effectiveness of long-acting inhaled beta- 2 agonists to support a general recommendation for use in children of any age [2]. See Table 1.

\section{Reliever medications}

Beta-2 agonists. Short-acting inhaled beta-2 agonists are the preferred reliever treatment for acute asthma in children. Numerous studies have established their bronchodilation and bronchoprotection effects in pre-school children and infants [61,70-82]. Dosing should be individualised, with monitoring of the therapeutic response and the occurrence of side effects to determine the effective dose [83].

Anticholinergics. Anticholinergics have a limited role in asthma management in children of any age. The evidence regarding the effect of anticholinergics in pre-school children is marginal $[84,85]$, and there is insufficient evidence to support the uncritical use of anticholinergics in infants [86].

Whilst rapid-acting inhaled reta 20 sonsts are the relievers of chcire, Ether agents provide alternatives $\perp \in n$ ti.ese agents are not available. (II) or def of increasing cost, they would be: inhaled anticholin moics, incert-acting oral beta-2 agonists; anislicert-acting theophyllines.

\section{Management of acute exacerbations}

Successful management of acute asthma exacerbations in pre-school children hinges on initiation of appropriate therapy at the earliest possible signs of deteriorating asthma control, with close monitoring of the patient's condition and response to treatment. All those responsible for the child's care should have a written action plan that outlines how to recognise signs of deterioration, modify or increase treatment, assess the severity of the attack, and obtain emergency medical care. The aims of treatment in acute exacerbations are to relieve airflow obstruction and any hypoxemia as quickly as possible, as well as to plan the prevention of future relapses. Treatment of acute exacerbations depends on several factors, including the experience of the health care professional, therapies that are most effective for the particular patient, availability of medications, and emergency facilities. The severity of the exacerbation determines the course of treatment.

Once the child has stabilised, full recovery from the exacerbation is usually gradual, and it may take 
Table 1 Summary of Recommended Stepwise Asthma Management in Primary Care for Children <6 Years, by Level of Asthma Severity [2]

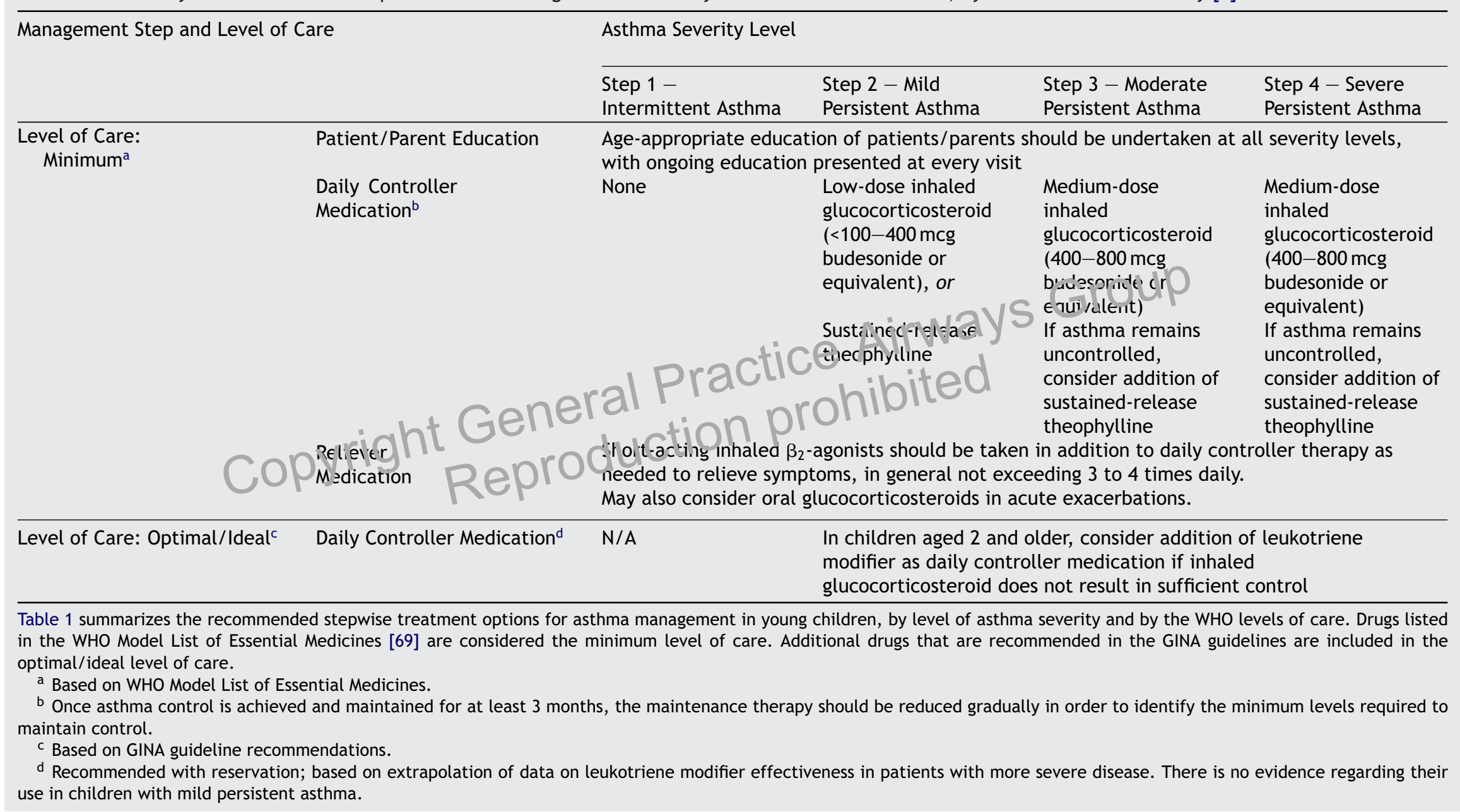


several days to regain normal lung function, and weeks for airway hyper-responsiveness to decrease.

Mild attacks can be treated at home. When this is done, the child's regular physician should be sought as promptly as possible for assessment and monitoring following acute treatment. Parents of young children with asthma should seek immediate medical care for the child if:

- The attack is severe

- There is not a prompt response to the initial bronchodilator treatment

- There is no improvement within 2 to 6 hours after initiation of oral corticosteroid treatment

- There is further deterioration.

Because PEF measurements are typically not useful in young children, the ability to monitor the child's response to treatment is limited to monitoring symptoms alone. Additionally, differences in lung anatomy and physiology place infants at greater risk than older children for respiratory failure. Thus, carers should have a low threshold for seeking professional assistance, and primary care physicians should not hesitate to refer the child to hospital when the severity of the exacerbation requires hospital care. Therapy should, however, be initiated promptly, even if the hospital is nearby.

\section{Home management}

The main thela, ies for exaserbations are short-acting inhaled keto-? agonists for bronchodilation and oral corticosteroids early in the course of a moderate or severe attack in order to reverse inflammation and promote recovery [87] ${ }^{* *}$. The use of antibiotic therapy in children with an exacerbation of asthma needs careful consideration by the physician as this is seldom necessary. After initial therapy, either the physician or the family should monitor the child until considerable improvement of symptoms has been achieved. When, despite adequate treatment, there is no improvement of symptoms after a maximum of six hours, or there is deterioration, the child should be referred to hospital.

\section{Conclusion and recommendations}

Once asthma is diagnosed it should be classified as being intermittent, mild persistent, moderate persistent, or severe persistent, and treated accordingly. The treatment goals are to relieve symptoms, to prevent exacerbations, to allow normal activity levels, to avoid adverse effects from medication, and to prevent disease progression and mortality. This IPCRG asthma management guideline is in line with GINA recommendations [2]. It has been structured in such a way that it can be used in different circumstances in different areas of the world with different healthcare systems, and is therefore applicable for use in primary care settings worldwide. In particular, it is unique in that it contains specific primary care guidance for the management of pre-school children, given that the diagnosis of asthma is difficult in children under the age of 6 and that the respiratory healthcare needs of pre-school children continue to increase.

\section{Potential conflicts of interest}

Thys van der Molen has no shares in pharmaceutical companies. He has received research grants and/or honoraria for speaking at sponsored meetings or for advisory panels from; Altana Pharma, BI, Astra Zeneca, GlaxoSmithKline and MSD.

Funding: During the development of these guidelines, the IPCRG received unrestricted educational grants from Altana, A. rilieneca, Boehringer Ingelheim, EAMG, SlaxoSmithKline, Merck Sharn anc' Donne, Mitsubishi Pharma, NCVartis, UCB Pharma and Zambon. These funds were used for to $\in$ Dirpose of funding face-to-face mee ing and also to support a secretariat.

\section{References}

[1] The International Primary Care Airways Group (IPAG). Diagnosis and management handbook. Chronic airways diseases: A guide for primary care physicians. January 2005. MCR Vision Inc. Also available at the URL http://www.ipagguide.org/.

[2] Global Strategy for Asthma Management and Prevention NIH Publication No 02-3659 Issued January, 1995 (updated 2002) Management Segment (Chapter 7): Updated 2005 from the 2004 document. The GINA reports are available at URL http: / /www. ginasthma.org.

[3] Levy ML, Fletcher M, Price DB, et al., International Primary Care Respiratory Group (IPCRG) Guidelines: Diagnosis of respiratory diseases in primary care. Prim Care Resp J 2006;15(1):20-34.

[4] Bellamy D, Henrichsen S, Johansson G, et al. International Primary Care Respiratory Group (IPCRG) Guidelines: Management of Chronic Obstructive Pulmonary Disease (COPD). Prim Care Resp J 2006;15(1):48-57.

[5] Price D, Bond C, Bouchard J. International Primary Care Respiratory Group (IPCRG) Guidelines: Management of allergic rhinitis. Prim Care Resp J 2006;15(1):58-70.

[6] Royal College of General Practitioners. The development and implementation of clinical guidelines. Report of the clinical guidelines working group. London, 1995. RCGP.

[7] Rabe KF. Worldwide severity and control of asthma in children and adults: the global asthma insights and reality surveys. J allergy Clin Immunol 2004;114(1):40-7. 
[8] Bateman ED. Achieving guideline-based asthma control: does the patient benefit? Eur Respir J 2002;20(3):588-95.

[9] Hesselink AAEPBB. Effectiveness of an education programme by a general practice assistant for asthma and COPD patients: results from a randomised controlled trial. PatEduc Couns 2004;55(1):121-8.

[10] Barnes PJ, Pedersen S, Busse WW. Efficacy and safety of inhaled corticosteroids. New developments. Am J Respir Crit Care Med 1998;157(3 Pt 2):S1-53.

[11] Douma WR. Initial improvements in lung function and bronchial hyperresponsiveness are maintained during 5 years of treatment with inhaled beclomethasone dipropionate and terbutaline. Chest 2002;121(1): 151-7.

[12] Suissa S. Regular use of inhaled corticosteroids and the long term prevention of hospitalisation for asthma. Thorax 2002;57(10):880-4.

[13] Dolovich MB. Device selection and outcomes of aerosol therapy: Evidence-based guidelines: American College of Chest Physicians/American College of Asthma, Allergy, and Immunology. Chest 2005;127(1):335-71.

[14] Newman SSS. Self-management interventions for chronic illness. Lancet 2004;364(9444):1523-37.

[15] Janson C. The effect of passive smoking on respiratory health in children and adults. Int $\mathrm{J}$ Tubercul Lung Dis 2004;8(5):510-6.

[16] Pipari R. Smoking and asthma in adults. Eur Respir J 2004;24(5):734-9.

[17] Rijssenbeek-Nouwens LH. Clinical evaluation of the effect of anti-allergic mattress covers in patients with moderate to severe asthma and house dust mite allergy: a randomised double blind placebo controlled study. Thorax 2002;57(9):784-90.

[18] Kerstjens HA, Brand PL, Hughes MD, et al. A compari on of bronchodilator therapy with or vitac u ir.haled corticosteroid therapy $\mathrm{fc}_{\mathrm{C}} \mathrm{o}$ sir $\mathrm{ctive}$ airways disease. Dutch Chronic N'ol . Sp e if c Lung Disease Study Crhu, Ise omr ents1 N Engl Jined 19\%2;27? (1):1113-9.

[19] Lipworth BJ. Systemic aiverse tffects of inhaled corticosteroid therapy: A systematic review and metaanalysis. Arch Inter Med 1999;159(9):941-55.

[20] Kemp JP. Recent advances in the management of asthma using leukotriene modifiers. Am J Respir Med 2003;2(2):139-56.

[21] NAEPP Expert panel report, managing asthma during pregnancy: Recommendations for pharmacologic treatment-2004 update. J Allergy Clin Immunol 2005; 115:34-46.

[22] Gluck JC. Asthma controller therapy during pregnancy. Am J Obstet Gynecol 2005;192(2):369-80.

[23] Masoli M. Optimal starting dose of inhaled corticosteroids in adult asthma: why has it taken so long? Thorax 2005;60(2):93-4.

[24] van der Molen T. Effects of the long acting beta agonist formoterol on asthma control in asthmatic patients using inhaled corticosteroids. The Netherlands and Canadian Formoterol Study Investigators. Thorax 1997;52(6):535-9.

[25] Pauwels RA. Effect of inhaled formoterol and budesonide on exacerbations of asthma. Formoterol and Corticosteroids Establishing Therapy (FACET) International Study Group. New Engl J Med 1997;337(20):1405-11.

[26] Bateman ED. Can guideline-defined asthma control be achieved? The Gaining Optimal Asthma ControL study. Am J Respir Crit Care Med 2004;170(8):836-44.

[27] Gibson PG. Monitoring the patient with asthma: an evidence-based approach. J Allergy Clin Immunol 2000;106(1 Pt 1):17-26.
[28] Tattersfield AE. Exacerbations of asthma: a descriptive study of 425 severe exacerbations. The FACET International Study Group. Am J Respir Critic Care Med 1999;160(2):594-9.

[29] FitzGerald JM, Grunfeld A. Status asthmaticus. In: Lichtenstein LM, Fauci AS, editors. Current therapy in allergy, immunology, and rheumatology. 5th edition St. Louis, MO: Mosby; 1996. p. 63-7.

[30] Gibson PG, Wong BJ, Hepperle MJ, Kline PA, Girgis-Gabardo $A$, Guyatt $G$, et al. A research method to induce and examine a mild exacerbation of asthma by withdrawal of inhaled corticosteroid. Clin Exp Allergy 1992;22:525-32.

[31] Turner MO, Noertjojo K, Vedal S, Bai T, Crump S, FitzGerald JM. Risk factors for near-fatal asthma. A case-control study in hospitalized patients with asthma. Am J Respir Crit Care Med 1998;157:1804-9.

[32] Ernst P, Spitzer WO, Suissa S, Cockcroft D, Habbick B, Horwitz RI, et al. Risk of fatal and nearfatal asthma in relation to inhaled corticosteroid use. JAMA 1992;268:3462-4.

[33] Suissa S, Blais L, Ernst P. Patterns of increasing beta-agonist use and the risk of fatal or near-fatal asthma. Eur Respir $J$ 1994;7:1602-9.

[34] Joseph KS, Blais L, Ernst P, Suissa S. Increased morbidity and mortality related to asthma among asthmatic patients who use major tranquillisers. BMJ 1996;312:79-82.

[35] Geelhoed GC, Landau LI, Le Souef PN. Evaluation of SaO2 as a predictor of outcome in $\mathbf{2 8 0}$ children presenting with acute asthma. Ann Emerg Med 1994;23:1236-41.

[36] Turner MO, Taylor D, Bennett R Et ?Ceradd.M. A randomized trial comparng peak expiratory flow and

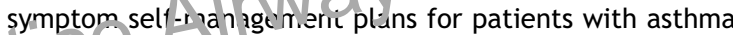
it $\in$ nding a primary care clihic. Am J Respir Crit Care Med 1998; 157:540

[37] Cater (J, Rcue EH. Holding chambers versus nebulisers $f(r)$ beta-agonist treatment of acute asthma. Cochrane Database Syst Rev 2000:2.

[38] Turner MO, Patel A, Ginsburg S, FitzGerald JM. Bronchodilator delivery in acute airflow obstruction. A meta-analysis Arch Intern Med 1997;157:1736-44, 2000;343:332-36.

[39] Turner MO, Gafni A, Swan D, FitzGerald JM. A review and economic evaluation of bronchodilator delivery methods in hospitalized patients. Arch Intern Med 1996;156: 2113-8.

[40] Foresi A, Morelli MC, Catena E. Low-dose budesonide with the addition of an increased dose during exacerbations is effective in long-term asthma control. On behalf of the Italian Study Group. Chest 2000;117:440-6.

[41] Madge P, McColl J, Paton J. Impact of a nurse-led home management training programme in children admitted to hospital with acute asthma: a randomised controlled study. Thorax 1997; 52:223-8.

[42] Strachan DP, Cook DG. Health effects of passive smoking. 1. Parental smoking and lower respiratory illness in infancy and early childhood. Thorax 1997;52:905-14.

[43] Strachan DP, Cook DG. Health effects of passive smoking. 5. Parental smoking and allergic sensitisation in children. Thorax 1998;53:117-23.

[44] Gotzsche PC, Johansen HK, Hammarquist C, Burr ML. House dust mite control measures for asthma. Cochrane Database Syst Rev 2001;(2):CD001187.

[45] Gotzsche PC, Hammarquist C, Burr M. House dust mite control measures in the management of asthma: metaanalysis. BMJ 1998;317:1105-10.

[46] Nielsen KG, Bisgaard $H$. The effect of inhaled budesonide on symptoms, lung function, and cold air and methacholine 
responsiveness in 2- to 5-year-old asthmatic children. Am J Respir Crit Care Med 2000;162(4 Pt 1):1500-6.

[47] Bisgaard H, Gillies J, Groenewald M, Maden C. The effect of inhaled fluticasone propionate in the treatment of young asthmatic children: a dose comparison study. Am J Respir Crit Care Med 1999;160:126-31.

[48] de Blic J, Delacourt C, Le Bourgeois M, et al. Efficacy of nebulized budesonide in treatment of severe infantile asthma: a double-blind study. J Allergy Clin Immunol 1996;98:14-20.

[49] Connett GJ, Warde C, Wooler E, Lenney W. Use of budesonide in severe asthmatics aged $1-3$ years. Arch Dis Child 1993;69:351-5.

[50] Noble V, Ruggins NR, Everard ML, Milner AD. Inhaled budesonide for chronic wheezing under 18 months of age. Arch Dis Child 1992;67:285-8.

[51] Bisgaard H, Munck SL, Nielsen JP, et al. Inhaled budesonide for treatment of recurrent wheezing in early childhood. Lancet 1990;336:649-51.

[52] Gleeson JG, Price JF. Controlled trial of budesonide given by the nebuhaler in preschool children with asthma. BMJ 1988;297:163-6.

[53] The Childhood Asthma Management Program Research Group. Long-term effects of budesonide or nedocromil in children with asthma. N Engl J Med 2000;343:1054-63.

[54] Agertoft L, Pedersen S. Effect of long-term treatment with inhaled budesonide on adult height in children with asthma. N Engl J Med 2000;343:1064-9.

[55] Van Bever HP, Desager KN, Lijssens N, et al. Does treatment of asthmatic children with inhaled corticosteroids affect their adult height? Pediatr Pulmonol 1999;27:369-75.

[56] Allen DB, Bronsky EA, LaForce CF, et al. Growth in asthmatic children treated with fluticasone propionate. Fluticasone Propionate Asthma Study Group. J Pediatr 1998.132:4 72 \%;.

[57] Price JF, Russell G, Hindmarsh DC et a. Govtn Juring one year of treatment ivith flu ica cne propionate or solitim cromoglva't $\epsilon$ in Cl idien with asthma. Pedict illmond $197724: 1 \% 3-86$.

[58] Silverstein $M D$, Yunginger $J N$, Re $=d$.E, et al. Attained adult height after childhood asthma: effect of glucocorticoid therapy. J Allergy Clin Immunol 1997;99:466-74.

[59] Doull IJ, Freezer NJ, Holgate ST. Growth of prepubertal children with mild asthma treated with inhaled beclomethasone dipropionate. Am J Respir Crit Care Med 1995;151:1715-9.

[60] Allen DB, Mullen M, Mullen B. A meta-analysis of the effect of oral and inhaled corticosteroids on growth. J Allergy Clin Immunol 1994;93:967-76.

[61] Daugbjerg P, Brenoe E, Forchhammer H, et al. A comparison between nebulized terbutaline, nebulized corticosteroid and systemic corticosteroid for acute wheezing in children up to 18 months of age. Acta Paediatr 1993;82:547-51.

[62] Brunette MG, Lands L, Thibodeau LP. Childhood asthma: prevention of attacks with short-term corticosteroid treatment of upper respiratory tract infection. Pediatrics 1988;81:624-9.

[63] Tal A, Levy N, Bearman JE. Methylprednisolone therapy for acute asthma in infants and toddlers: a controlled clinical trial. Pediatrics 1990;86:350-6.

[64] Tal A, Bavilski C, Yohai D, et al. Dexamethasone and salbutamol in the treatment of acute wheezing in infants. Pediatrics 1983;71:13-8.

[65] Pearlman DS, Lampl KL, Dowling Jr PJ, et al. Effectiveness and tolerability of zafirlukast for the treatment of asthma in children. Clin Ther 2000;22:732-47.

[66] Kemp JP, Dockhorn RJ, Shapiro GG, et al. Montelukast once daily inhibits exercise-induced bronchoconstriction in 6- to 14-year-old children with asthma. J Pediatr 1998;133:424-8.

[67] de Benedictis FM, Medley HV, Williams L. Long-term study to compare safety and efficacy of fluticasone propionate (FP) with beclomethasone dipropionate (BDP) in asthmatic children. Eur Respir J 1998;12:142S.

[68] Bisgaard H, Nielsen KG. Bronchoprotection with a leukotriene receptor antagonist in asthmatic preschool children. Am J Respir Crit Care Med 2000;162:187-90.

[69] World Health Organization. The 12th WHO Model List of Essential Medicines. Accessed July 2003 at URL: http://www.who.int/medicines/organization/par/edl/ eml.shtml.

[70] Yuksel B, Greenough A. Effect of nebulized salbutamol in preterm infants during the first year of life. Eur Respir $J$ 1991;4:1088-92.

[71] Kraemer R, Frey U, Sommer CW, Russi E. Short-term effect of albuterol, delivered via a new auxiliary device, in wheezy infants. Am Rev Respir Dis 1991;144:347-51.

[72] Yuksel B, Greenough A, Maconochie I. Effective bronchodilator treatment by a simple spacer device for wheezy premature infants. Arch Dis Child 1990;65:782-5.

[73] Nussbaum E, Eyzaguirre M, Galant SP. Dose-response relationship of inhaled metaproterenol sulfate in preschool children with mild asthma. Pediatrics 1990;85:1072-5.

[74] Ahlstrom H, Svenonius E, Svensson $M$. Treatment of asthma in pre-school children with inhalation of terbutaline in Turbuhaler compared with Nebuhaler. Allergy 1989;44:515-8.

[75] Conner WT, Dolovich MB, Frame RA, Nov hu $\in$ A.T. Reliable salbutamol adminictraco $n$ in 0 to so-month-old children by means it a $r$ et $r$ d uose inhaler and Aerochamber with nas. Pediatr Pulmonol 1)89;6:263-7.

[-16] Kao LC Duland D Plickerson BG. Effects of inhaled moripicteren 1 and atropine on the pulmonary mechanics of inrants with bronchopulmonary dysplasia. Pediatr Pulmonol 1989;6:74-80.

[77] O'Callaghan C, Milner AD, Swarbrick A. Nebulised salbutamol does have a protective effect on airways in children under 1 year old. Arch Dis Child 1988;63:479-83.

[78] Pool JB, Greenough A, Gleeson JG, Price JF. Inhaled bronchodilator treatment via the nebuhaler in young asthmatic patients. Arch Dis Child 1988;63:288-91.

[79] Wilkie RA, Bryan MH. Effect of bronchodilators on airway resistance in ventilator-dependent neonates with chronic lung disease. J Pediatr 1987;111:278-82.

[80] Prendiville A, Green S, Silverman M. Airway responsiveness in wheezy infants: evidence for functional beta adrenergic receptors. Thorax 1987;42:100-4.

[81] Cabal LA, Larrazabal C, Ramanathan R, et al. Effects of metaproterenol on pulmonary mechanics, oxygenation, and ventilation in infants with chronic lung disease. J Pediatr 1987;110:116-9.

[82] Sosulski R, Abbasi S, Bhutani VK, Fox WW. Physiologic effects of terbutaline on pulmonary function of infants with bronchopulmonary dysplasia. Pediatr Pulmonol 1986;2:269-73.

[83] Morgan DJ. Clinical pharmacokinetics of beta-agonists. Clin Pharmacokinet 1990;18:270-94.

[84] Ducharme FM, Davis GM. Randomized controlled trial of ipratropium bromide and frequent low doses of salbutamol in the management of mild and moderate acute pediatric asthma. J Pediatr 1998;133:479-85.

[85] Groggins RC, Milner AD, Stokes GM. Bronchodilator effects of clemastine, ipratropium, bromide, and salbutamol in preschool children with asthma. Arch Dis Child 1981;56:342-4. 
[86] Everard ML, Bara A, Kurian M. Anti-cholinergic drugs for wheeze in children under the age of two years. Cochrane Database Syst Rev 2000;(2): CD001279.

[87] FitzGerald JM, Grunfeld A. Status asthmaticus. In: Lichtenstein LM, Fauci AS, editors. Current therapy in allergy, immunology, and rheumatology. 5th edition St. Louis, MO: Mosby; 1996. p. 63-7.

[88] Harrison B, Stephenson P, Mohan G, Nasser S. An ongoing Confidential Enquiry into asthma deaths in the Eastern Region of the UK, 2001-2003. Prim Care Resp J 2005;14(6):303-13.

Available online at www.sciencedirect.com

science 0 Direct

\section{Available online at http://www.thepcrj.org}

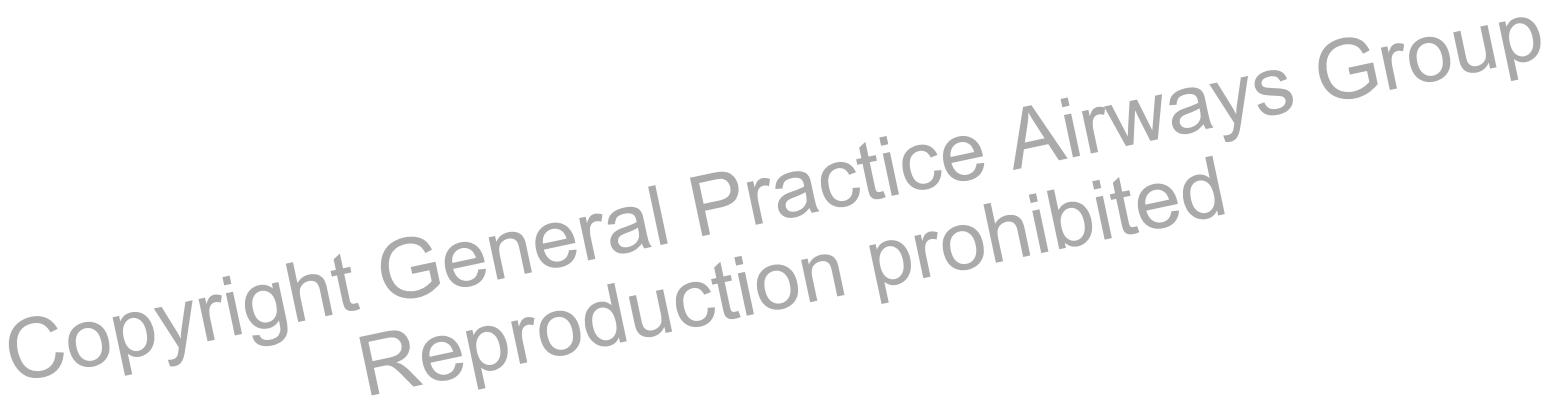

